\title{
EFFECT OF USING MINERALIZED DENTIN PARTICULATE GRAFTED FOR SOCKET PRESERVATION
}

\author{
Ahmed M Fathy *, Mohamed H. Abd-ElAkher ${ }^{* *}$, Ahmed A. Elfeky ***
}

\begin{abstract}
Objective: This study was designed to evaluate the effect of using mineralized dentin particulate grafted for socket preservation. Patients and methods: The study was conducted on 20 patients seeking extraction of at least one hopeless tooth, they were randomly distributed into two groups, 10 patients in graft (test) group, and 10 patients for control group. In graft group, mineralized dentin graft was used as socket preservation, in control group, the socket was left to heal spontaneously by clot formation. Panoramic $\mathrm{x}$-ray was taken for all patients before extraction, CBCT images were taken for all patients in two intervals, a- immediate postoperative, b- 6 months post-operative. CBCT images were used to compare horizontal and vertical ridge dimensions, and bone density values immediately post-operative and after 6 months of extraction. Results: There was statistically significant decrease in horizontal and vertical ridge dimensions in both groups after 6 months, but the decrease of vertical and horizontal ridge dimensions in control group was statistically significantly higher than that in graft group, also bone density of graft group was statistically significantly higher than that of the control group after 6 months. Conclusion: Mineralized dentin particulate can be used as a good autogenous graft material for socket preservation giving promising results in reducing vertical and horizontal bone loss, and favorable bone density values after 6 months.
\end{abstract}

Key Words: mineralized dentine particulates, grafts, socket preservation

\section{INTRODUCTION}

Bone resorption and loss of vertical and horizontal dimensions of the alveolar ridge is main drawback that follows tooth extraction. The mean horizontal bone loss after six months was $3.87 \mathrm{~mm}$, the mean vertical bone loss was $1.67 \mathrm{~mm}$. This bone resorption negatively affects the restoration of the edentulous space either by fixed restorations, removable restorations or implant both functionally and esthetically ${ }^{(1,2)}$. Socket preservation is a technique used to keep the bone loss as low as possible. Many procedures can be done including atraumatic tooth extraction, soft and hard tissue grafting, concomitant use of barrier membranes and immediate implant placement ${ }^{(3)}$.

Autogenous bone graft is the gold standard type of grafts, as it is the only type of grafts that possesses all graft properties; osteoinductive, osteoconductive and osteogenesis. However, secondary surgical sites, pain, high rates of donor site morbidity, and limited supply of graft material are the main disadvantages of autogenous graft ${ }^{(4)}$.

Allografts solve several of the disadvantages of autogenous grafts, they are osteoinductive and osteoconductive, but still carry the risk of cross infection. Xenografts and alloplastic graft materials are only osteoconductive, but they give adequate amounts of graft ${ }^{(5-7)}$.

Dentin graft was first introduced in 1967, in a study used decalcified dentin graft(DDG) in muscles, mandibular osseous defects, and alveolar socket, the study showed very promising results ${ }^{(8)}$. Dentin and alveolar bone share the same embryological origin, and similar chemical structure, both has $65 \%$

* Dentist at Ministry of health.

** Professor of Oral and Maxillofacial Surgery and Dean of Faculty of Dentistry, Boys, Cairo, Al-Azhar University.

*** Assistant Professor of Oral and Maxillofacial Surgery, Faculty of Dental Medicine, Boys, Cairo, Al-Azhar University. 
inorganic substance, and 35\% organic substance and water, and both are originated from neural crest (9). DDG is thought to be good graft material that can substitute existing autogenous bone graft materials, it can be easily and readily available, with minimal risk of infection, and donor site morbidity as no vital bone is sacrificed, it can be easily shaped to fit into the boney defect, it can be used as block or powder forms ${ }^{(10,11)}$. Demineralization process takes days to weeks to be sent to Korea Tooth Bank ${ }^{\circledR}$ to be crushed and demineralized ${ }^{(12)}$.

\section{PATIENT AND METHODS}

Patients of the present study were selected from those attending the outpatient clinic of Oral and Maxillofacial Department, Faculty of Dental Medicine, Boys, Al-Azhar University, Cairo, seeking treatment for their badly broken or impacted teeth. Study sample of this study included 20 cases, 11 males and 9 females, ranging in age from 22 to 63 years, with mean age of 37 years.

\section{Pre-operative evaluation:}

Digital panoramic radiograph was done to evaluate the condition of the teeth, the tooth to be extracted, and to evaluate the alveolar bone at the site of extraction. Intra-oral evaluation of the tooth to be extracted and alveolar ridge condition at the site of extraction was done for each patient. Each patient signed a written consent having all the details about the surgical procedures.

\section{Surgical procedures}

Patients were randomly divided into two groups: graft group (test group) and control group, each group had 10 patients.

In graft group: The non-restorable or impacted tooth was extracted as atraumatic as possible under local anesthesia.

\section{Graft preparation}

1. Granulation tissue, debris, caries, restorations, and periodontal ligaments were removed from the extracted tooth surface by using a carbide bur.

2. The cleaned tooth was then put in the grinding chamber of the Smart Dentin Grinder (CT Dent, London, UK) (Fig.1) to be grinded for 3 seconds, followed by vibration for 10 seconds to allow the particles within size of 300-1200 $\mu \mathrm{m}$ to pass through the sieve and keep the lager particles for further grinding. Particles of size less than $300 \mu \mathrm{m}$ passed though the lower sieve to the waste chamber and discarded.

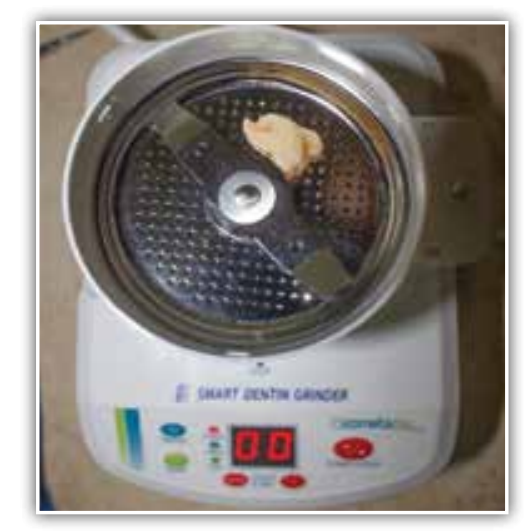

Fig. (1) Showing cleaned tooth in grinding chamber.

3. The grinded particles were immersed in dentin cleanser solution which consists of $0.5 \mathrm{M}$ of $\mathrm{NaOH}$ and 30\% alcohol (v/v) for 10 minutes for defatting, dissolving all organic debris, bacteria and toxins of the dentin particles

4. The graft was then washed twice with sterile phosphate buffered saline.

5. The graft was ready to be placed into the socket and the wound was sutured using resorbable vicryl 4.0 suture.

In control group: The tooth was extracted as atraumatic as possible and the socket was left to heal spontaneously by clot formation. 


\section{Post-operative follow-up:}

Clinically: All patients were recalled after one week for suture removal and check healing and if there were any postoperative complications.

Radiographically: Radiographic assessment was done by CBCT taken at two stages; 1st stage immediately after extraction as a baseline image, and after six months to be compared to the baseline, to calculate differences in ridge width and height, difference in bone density before and after extraction in both groups. Bone density was measured according to Carl Misch hounsfield units (HU) chart.

\section{RESULTS}

All cases healing was uneventful for both groups, only 1 patient complained of wound dehiscence, she was treated by normal saline flush and antibiotics. And responded well to the treatment.

Using mineralized dentin graft offers favorable quantity of graft material, molar teeth gave average of 2 grams of graft material

There was statistically significant decrease of horizontal socket width after 6 months in both groups, however, this loss in the control group was statistically significantly higher than that in control group. This loss in control group was more than three and half times (3.5X) that in graft group. Also, after six months, the mean width of graft group was statistically significantly higher than in control group, (chart 1).

Although the vertical dimension loss in both groups statistically significant, however, this loss was much lower in the graft group compared to the control group. The amount of vertical dimension loss in control group was more than three times (3X) that happened in graft group. The loss of vertical socket height in graft group was statistically significantly lower than in control group, (chart 2) .
Bone density of graft group was statistically significantly higher than that of the control group after 6 months, (chart 3).

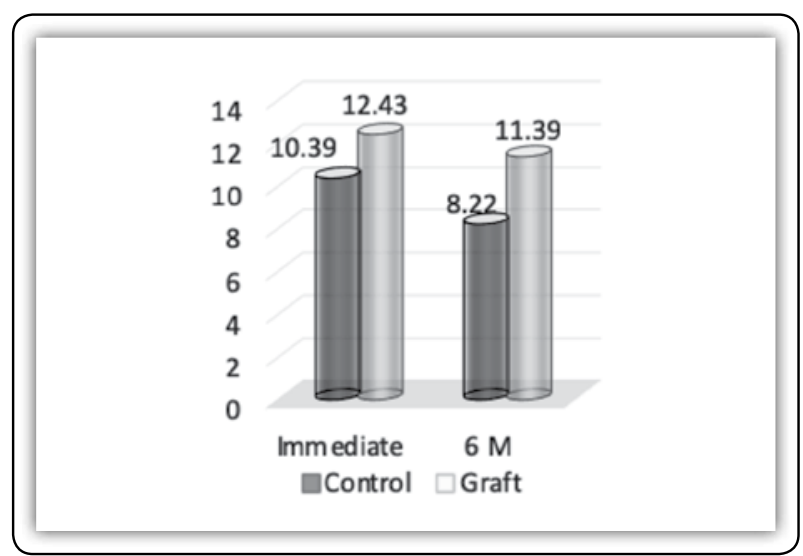

Chart 1 Mean values of horizontal socket immediately and 6 months postoperatively

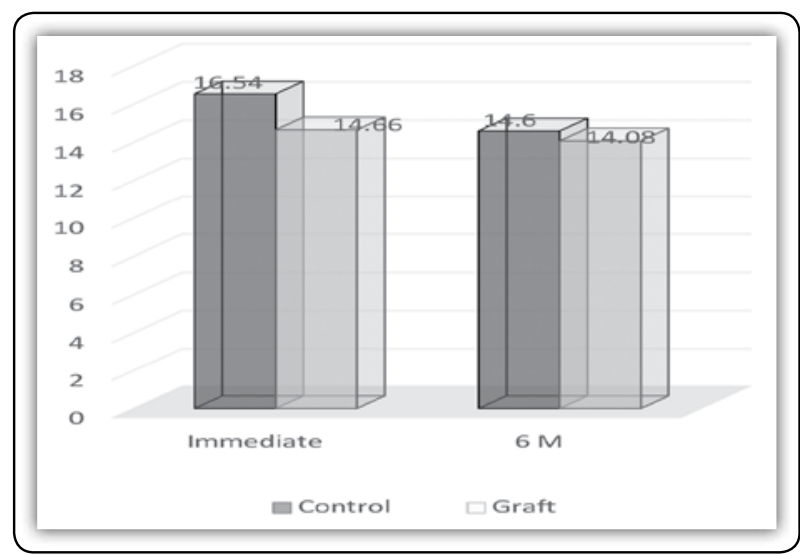

Chart (2) Mean values of vertical socket measurement immediately and 6 months postoperatively

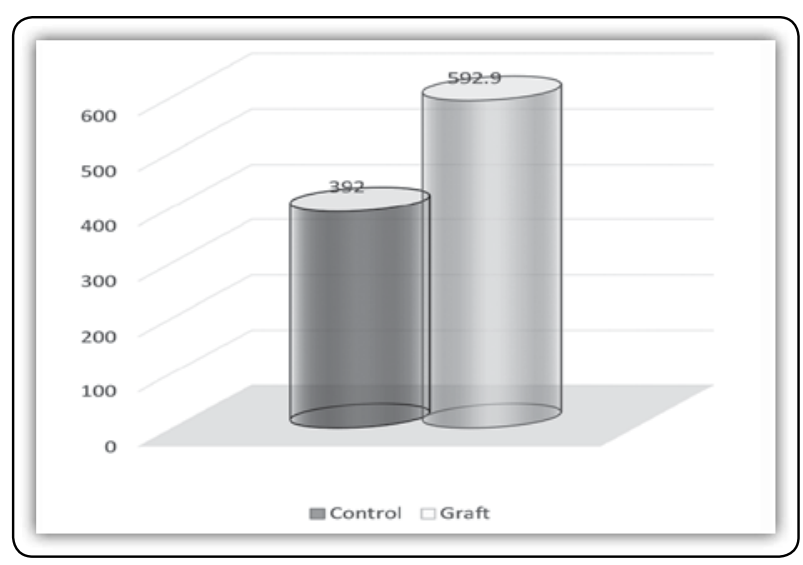

Chart (3) Mean values of bone density after 6 months 


\section{DISCUSSION}

Ridge alteration is a physiological process that must occur after either single or multiple teeth extraction. Alveolar ridge undergoes resorption in both vertical and horizontal aspects. This ridge loss starts after extraction and continues throughout life, its fastest rate during first three months, and then the rate decreases gradually. Resorption occurs spontaneously in both horizontal and vertical dimensions, but it is more rapid and aggressive in horizontal dimension than in vertical one. Many studies stated that about $50 \%$ of the horizontal dimension was lost after six months Vertical dimension decreases also, it decreases more rapidly on buccal side, after six months vertical dimension decreases by about $1.7 \mathrm{~mm}^{(13,14)}$.

By definition, socket preservation term is used when a graft material is used to fill a completely contained and undamaged sockets, while alveolar ridge preservation term is used to describe the technique used when damaged sockets are to be preserved or regenerated ${ }^{(15)}$.

In previous studies demineralized dentin was used as graft material, where the extracted tooth was sent to Korea Tooth Bank ${ }^{\circledR}$ to be crushed and subjected to a dehydration, defatting and demineralization processes and then lyophilized, then sterilized with ethylene oxide gas, then sent back to the clinic or hospital ${ }^{(16-18)}$. This process takes days to weeks to be done. In later studies, a more recent device $\left(\right.$ VacuaSonic $^{\circledR}$ ) used to produce demineralized dentin graft chairside, but the process takes minimum of two hours, which usually require a second surgery to continue the procedure ${ }^{(19)}$.

In the current study, after tooth extraction, the tooth was grinded using Smart Dentin Grinder ${ }^{\circledR}$ and washed by dentin cleanser then saline to be ready for grafting within 15-20 minutes. Saving time and money and eliminating the need for second operation or waiting for a long time before grafting.
Comparing resorption rates of many studies ${ }^{(20-26)}$ used various types of graft materials after excluding ridge augmentation results with rates of the current study, mineralized dentine particulate showed significant results that indicate that it can be relied on as a new autogenous graft material. Dentin graft can be used in socket preservation to reduce postextraction resorption rates to very favorable rates, losing only $0.59 \mathrm{~mm}$ of horizontal dimension using dentin graft that is better than all other graft types according to the previous studies, and better than allograft, xenograft, and alloplastic grafts in vertical dimension.

There was slight increase of bone density in graft group along the study period. This slight increase may be explained by formation of new bone within graft particles and slow resorption rate results in remaining graft particles with high density of dentin. This finding can explain the statistically significant difference in bone density between control and graft groups after 6 months.

In the current study mineralized dentin offers immediate bacteria free graft material in the same visit within only 15 minutes, with reduced cost and surgical steps. It provides hard graft material that integrates fast and rigidly to the host bone providing good site for implant insertion that maintain esthetic and ridge morphology for years, which goes in agreement with Dr Binderman findings in his study ${ }^{(27)}$.

\section{CONCLUSION}

Mineralized dentin particulate can be used as a good autogenous graft material that can substitute other autogenous graft material, it can be used for socket preservation giving favorable results reducing vertical and horizontal bone loss and gives high bone density values after 6 months. An extracted tooth should not be discarded any more. 


\section{REFERENCES}

1. Seibert J, Salama H. Alveolar ridge preservation and reconstruction. Periodontol 2000. 1996; 11:69-84.

2. Weijden FVD, Dellacqua F, Slot DE. Alveolar bone dimensional changes of post-extraction sockets in humans: a systematic review. J Clin Periodontol. 2009; 36:1048-58.

3. Darby I, Chen S, Poi RD. Ridge preservation: what is it and when should it be considered. Aust Dent J. 2008; 53:11-21.

4. Meyer U, Wiesmann HP, Neunzehn J, Joos U. Bone tissue engineering. In: Ferri J, Hunziker EB, editors. Preprosthetic and maxillofacial surgery. 1st ed. Cambridge (UK): Woodhead Publishing Limited; 2011. p. 1-24.

5. Stavropoulos A. Deproteinized Bovine Bone Xenograft. In: Pietrzak WS, editors. by. Musculoskeletal Tissue Regeneration. 1st ed. Totowa, NJ: Humana Press; 2008. p. 119-152.

6. Kumar P, Vinitha B, Fathima G. Bone grafts in dentistry. J Pharm Bioall Sci 2013; 5:125-7.

7. Fillingham Y, Jacobs J. Bone grafts and their substitutes Bone Joint J. 2016; 98:6-9.

8. Yeomans J, Urist M. Bone induction by decalcified dentine implanted into oral, osseous and muscle tissues. Arch Oral Biol. 1967; 12:999-IN16.

9. Kim Y-K, Lee J, Um I-W, Kim K-W, Murata M, Akazawa T. Tooth-derived bone graft material. J Korean Assoc Oral Maxillofac Surg. 2013; 39:103-111.

10. Abd El Akher M. Dentin as a reconstructive material in boney defects. Al- Azhar University, Cairo:; 1988.

11. Kim SK, Kim SW, Kim KW. Effect on bone formation of the autogenous tooth graft in the treatment of peri-implant vertical bone defects in the minipigs. Maxillofac Plast Reconstr Surg. 2015; 37:2-12.

12. Kim Y-K, Kim S-G, Byeon J-H, Lee H-J, Um I-U, Lim S-C. Development of a novel bone grafting material using autogenous teeth. Oral Surg Oral Med Oral Pathol Oral

13. Kim $\mathrm{YK}^{1}$, Kim SG, Byeon JH, Lee HJ, Um IU, Lim SC, Kim SY. Development of a novel bone grafting material using autogenous teeth. Radiol Endod. 2010;109(4):496-503.

14. Orgeas GV, Clementini M, Risi VD, Sanctis MD. Surgical Techniques for Alveolar Socket Preservation: A Systematic Review. Int J Oral Maxillofac Implants. 2013; 28:1049-61.

15. Horowitz R, Holtzclaw D, Rosen PS. A Review on Alveolar Ridge Preservation Following Tooth Extraction. J Evid Based Dent Pract. 2012; 12:149-60.

16. Willenbacher $\mathrm{M}, \mathrm{Al}-\mathrm{Nawas} \mathrm{B}$, Berres $\mathrm{M}$, Kämmerer PW, Schiegnitz E. The Effects of Alveolar Ridge Preser- vation: A Meta-Analysis. Clin Implant Dent Relat Res. 2015Jan;18(6):1248-68

17. Kim Y-K, Kim S-G, Oh J-S, Jin S-C, Son J-S, Kim S-Y. Analysis of the Inorganic Component of Autogenous Tooth Bone Graft Material. J. Nanosci. Nanotechnol. 2011Jan;11(8):7442-5.

18. Kim Y-K, Kim S-G, Yun P-Y, Yeo I-S, Jin S-C, Oh J-S. Autogenous teeth used for bone grafting: a comparison with traditional grafting materials. Oral Surg Oral Med Oral Pathol Oral Radiol 2014;117: e39-e45.

19. Kim Y-K, Yun P-Y, Um I-W, Lee H-J, Yi Y-J, Bae J-H. Alveolar ridge preservation of an extraction socket using autogenous tooth bone graft material for implant site development: prospective case series. J Adv Prosthodont 2014; 6:521-7.

20. Kim E-S. Autogenous fresh demineralized tooth graft prepared at chairside for dental implant. Maxillofac Plast Reconstr Surg. 2015; 37:8-13.

21. Horváth A, Mardas N, Mezzomo LA, Needleman IG, Donos N. Alveolar ridge preservation. A systematic review. Clin Oral Investig. 2012; 17:341-63.

22. Fiorellini J, Howell T, Cochran D, Malmquist J, Lilly L, Spagnoli D. Randomized Study Evaluating Recombinant Human Bone Morphogenetic Protein-2 for Extraction Socket Augmentation. J Periodontol. 2005; 76:605-613.

23. Barone A, Aldini NN, Fini M, Giardino R, Guirado JLC, Covani U. Xenograft Versus Extraction Alone for Ridge Preservation After Tooth Removal: A Clinical and Histomorphometric Study. J Periodontol. 2008; 79:1370-7.

24. Aimetti M, Romano, F, Griga FB, Godio L. Clinical and histologic healing of human extraction sockets filled with calcium sulfate. Int J Oral Maxillofac Implants. 2009; 24:902-9.

25. Crespi R, Capparè P, Gherlone E. Magnesium-Enriched Hydroxyapatite Compared to Calcium Sulfate in the Healing of Human Extraction Sockets: Radiographic and Histomorphometric Evaluation at 3 Months. J Periodontol. 2009; 80:210-8.

26. Poulias E, Greenwell H, Hill M, Morton D, Vidal R, Shumway B. Ridge Preservation Comparing a Socket Allograft Alone to a Socket Allograft Plus a Facial Overlay Xenograft: A Clinical and Histologic Study in Humans. J Periodontol. 2013; 84:1567-75.

27. Binderman I, Hallel G. A Novel Procedure to Process Extracted Teeth for Immediate Grafting of Autogenous Dentin. J Interdiscipl Med Dent Sci. 2014; 02:154-8. 